\title{
Termos e características associadas à competência. Estudo comparativo de profissionais do desporto que exercem a sua actividade profissional em diferentes contextos de prática desportiva
}

\author{
Paula M. Batista \\ Amândio Graça \\ Zélia Matos
}

https://doi.org/10.5628/rpcd.08.03.377

\section{RESUMO}

Actualmente novos contextos de exercício profissional ganham espaço e significado para o profissional do desporto. A profissão complexifica-se requerendo profissionais competentes capazes de responder às novas exigências. A falta de consenso em torno do conceito de competência adquire maior visibilidade, impelindo a procura de elementos que contribuam para a (re)construção de um conceito de competência aplicável ao renovado campo de intervenção do profissional do desporto. Este estudo tem como principal propósito contribuir para a identificação do campo nocional que rodeia o conceito de competência em quatro áreas de intervenção do profissional do desporto - Educação Física, Treino Desportivo, Fitness e Actividade Física Adaptada. Foram entrevistados 120 profissionais (30 de cada área ocupacional) sobre os termos e características que associam à competência. $\mathrm{Na}$ análise dos dados recorreu-se aos procedimentos de análise de conteúdo. Os resultados indicam a existência de uma grande diversidade de termos e características associadas à noção de competência, sendo que a dimensão ética ocupa um lugar proeminente e o conhecimento se assume como elemento nuclear em todas as áreas ocupacionais.

Palavras-chave: conceito de competência, competência profissional, conhecimento, profissões do desporto

\author{
Universidade do Porto \\ Faculdade de Desporto \\ Portugal
}

\begin{abstract}
Terms and characteristics associated with competence. Comparative study among sport's professionals who work in different contexts of sport

Nowadays new contexts of professional intervention are gaining space and meaning for sports professionals. The profession is growing in complexity, requiring competent professionals able to answer to these new requirements. The lack of consensus around the concept of competence acquires greater visibility and urges the search for the elements that can contribute to the (re)construction of a valid and useful concept of competence, with potential to renovate professional field of sport. The main purpose of this study was to inspect the concept of competence ruling in four professional sports areas: Physical Education, Fitness, Coach training, and Adapted Physical Activity. A hundred and twenty sport professionals (30 by occupational area) were interviewed about the terms and characteristics they associate to competence. Content analysis procedures were used in data analysis. The results show a wide variety of terms and characteristics associated with the notion of competence, revealing the prominent place of ethical dimension and knowledge as a core component in all occupational areas.
\end{abstract}

Key-words: concept of competence, professional competence, knowledge, sport occupational areas 


\section{INTRODUÇÃO}

O termo competência acompanha-nos desde épocas remotas. Segundo Mish(30), 'competência' surgiu pela primeira vez no Webster's Dictionary em 1596 tendo, desde então, sido objecto de diversas definições lexicógrafas. Clark ${ }^{(10)}$ analisou as definições de competência apresentadas no Oxfort English Dictionary(32) no MacMillan's Modern Dictionary(35) no Swan's Anglo-American Dictionary(41); e no Merriam Webster's Collegiate Dictionary( ${ }^{(30)}$, denotando a convergência das definições em torno das ideias de suficiência, qualificação, aptidão, capacidade, ou condição (state of being) (p.32-33).

$\mathrm{O}$ termo competência foi elevado à categoria de conceito científico, no campo da linguística, quando foi introduzida a distinção entre a competência e a performance dos falantes de uma língua ${ }^{(9)}$.

McClelland(27), apontado como precursor da competência ocupacional, considerava que os resultados importantes alcançados na vida não dependiam necessariamente da inteligência, assim como discordava da associação assumida entre ser competente e possuir qualificações académicas. Advogou a substituição dos testes de inteligência por uma avaliação centrada nos comportamentos, o que abriu caminho à mudança do paradigma da qualificação para o paradigma da competência e deu azo ao crescimento exponencial da literatura sobre a competência, nos mais diversos contextos de aplicação e sob as mais diversas perspectivas.

Schippmann, Ash, Carr, Eyde, Hesketh, Kehoe, Pearlman e Prien (40) constataram o uso extensivo e precoce do termo competência na literatura psicológica, termo que se teria estendido sucessivamente do âmbito do direito para outros contextos, nomeadamente a psicologia clínica, a orientação vocacional, a educação e a psicologia industrial, e que definiria quer o desempenho bem sucedido de tarefas ou actividades, quer o domínio "adequado" de uma área de conhecimento ou capacidade.

Porém, a aparente simplicidade do conceito de competência não passa disso mesmo. É que a competência continua a revelar-se como um conceito pouco pacífico, tanto ao nível da conceptualização, como da sua utilização, que se faz de forma muito pouco rigorosa, se não mesmo indiscriminada $(1,48)$. Acrescendo a esta falta de clarificação, a literatura evidencia uma profusão de termos utilizados como sinónimos de competência e uma grande diversidade de termos utilizados para definir o próprio conceito de competência Refira-se a título ilustrativo o termo "competências" considerado por Parente(33) sinónimo de "competência" e a definição de competência de Parry(34) que é "composta" por termos - conhecimento, habilidades e atitudes. O recenseamento e arrumação destes termos revela-se uma tarefa difícil, se não mesmo impossível, se acrescentarmos à enorme diversidade a polissemia dos termos empregues (e. g. conhecimento, habilidades, eficiência, desempenho, qualificação, certificação, capacidade, atitudes, comportamentos, padrões, perito, tarefas, papéis, contexto, reflexão, profissionalismo, entre outros).

\section{Definições de competência}

A necessidade de identificar o campo nocional ${ }^{1}$ da competência, tal como já referenciamos em estudo anterior, em que tratamos as questões relacionadas com o significado e conceito de competência ${ }^{2}$, revela-se essencial na exploração de um conceito com vista à sua utilização noutros contextos. Pensamos que a captação dos termos e das expressões semiconceptualizadas permite fazer um ponto da situação acerca do que rodeia este conceito tão pouco consensual e com contornos tão indefinidos.

Apesar desta grande diversidade e do pouco significado que representa a apresentação de definições de competência, procuraremos apresentar algumas definições que marcaram o percurso conturbado do entendimento de competência, dando evidência à diversidade de termos utilizados, acrescido dos termos utilizados como sinónimos de competência. Wiemann e Backlund(52) e Keen ${ }^{(19,52)}$ consideram que a competência é a capacidade de escolher entre um conjunto de comportamentos disponíveis, procurando alcançar com sucesso os objectivos visados, dentro dos constrangimentos da situação Numa definição metafórica(19): "Competence is compound, made up of different parts just like the fingers of a hand (i.e, skills, knowledge, experience, contacts, values and additionally coordination which is located in the palm, and supervision, symbolized by nervous system." (p.112) Spitzberg(44) entende a competência como um sistema lato que envolve a forma como a motivação, o conhecimento e as habilidades se relacionam para se 
Quadro 1. Síntese dos termos referenciados nas definições de competência

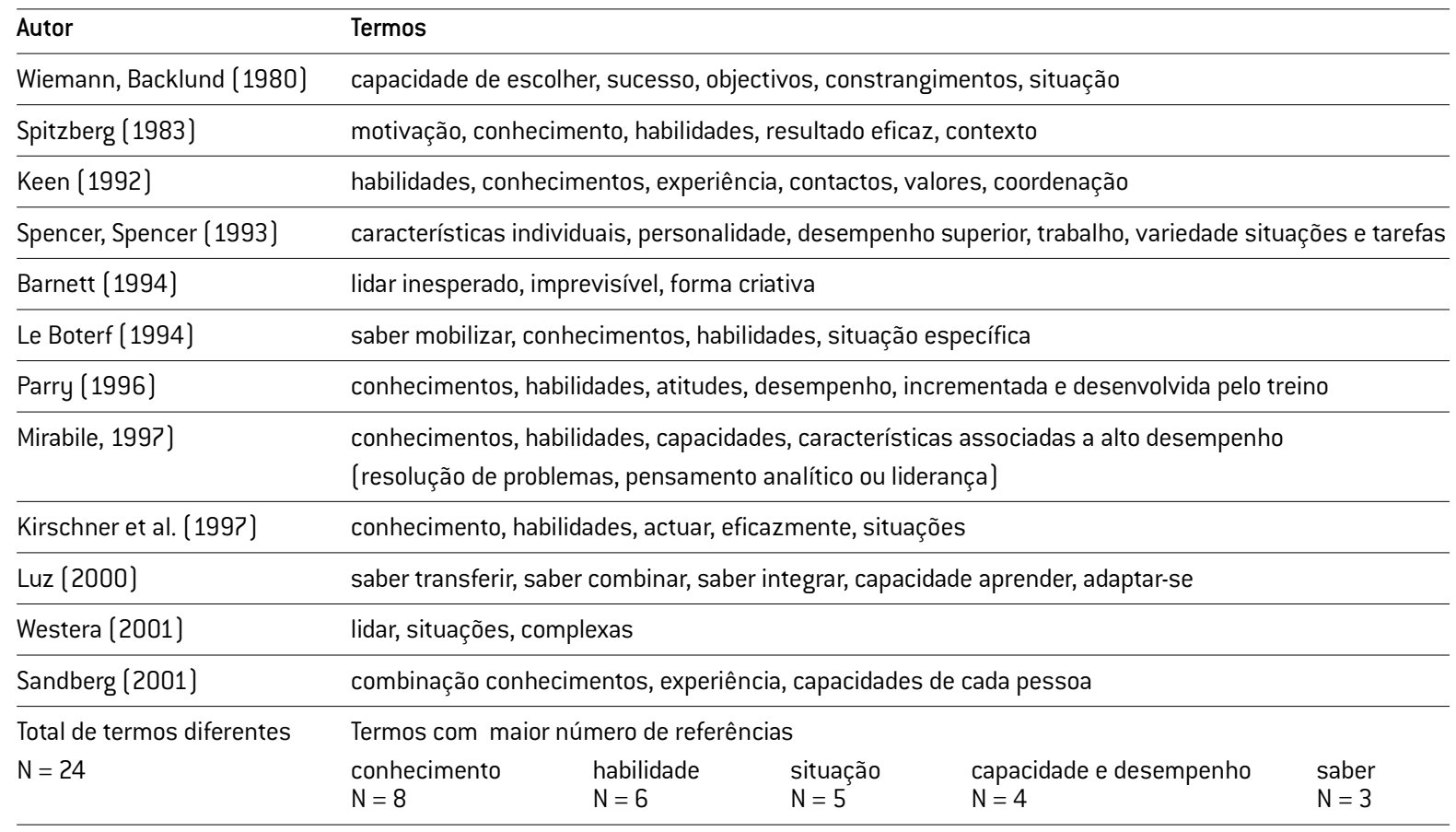

traduzirem em resultados eficazes em função das particularidades do contexto.

Spencer e Spencer(43) apresentam uma definição muito centrada nas características pessoais:

A competency is an underlying characteristic of an individual that is causally related to criterion-referenced effective and/or superior performance in a job or situation.

Underlying characteristics means the competency is a fairly deep and enduring part of a person's personality and can predict behaviours in a wide variety of situations and job tasks. Causally related means that a competency actually predicts who does something well or poorly, as measured on a specific criterion or standard. (p.9)

Parry) (34) apresenta uma definição assente na relação entre os elementos da competência:

(...) a cluster of related knowledge, skills and attitudes that affects a major part of one's job (a role or responsibility), that correlates with performance on the job, that can be measured against well-accepted standards, and that can be improved via training and development. (p.50).

Mirabile(29) associa o conceito a desempenhos elevados, referindo que "Competency is a knowledge, skill, ability, or characteristic associated with high performance on a job, such as problem solving, analytical thinking, or leadership. Some definitions of a competency include motives, beliefs and values" (p.75). Competência é considerada a capacidade de tomar decisões satisfatórias e eficazes numa situação ou realidade específica(20). Le Boterf(22) considera que a competência é um saber mobilizar conhecimentos e habilidades numa situação específica e que sofre interferências directas da situação específica em que a acção decorre. Luz(24) denuncia o mesmo tipo de entendimento quando refere que "ser competente é saber transferir, saber combinar e integrar, supõe a capacidade de aprender e adaptar$s e$ " (p.46). Barnett ${ }^{(2)}$ refere que uma parte crítica do conceito de competência é lidar com o inesperado e o imprevisível de uma maneira criativa. Por sua vez, Sandberg(39) olha a competência como uma combinação de conhecimento, experiências e capacidades de cada pessoa: "competence as a combination of a person's knowledge, experiences and abilities” (p.103). A competência é então vista como uma definição pragmática que contém: conhecimento - o que se pode aprender 
no processo de educação; experiência - o que se recolhe no emprego, no local de trabalho e na vida social e capacidades - para usar o conhecimento e a experiência.

Apesar de reduzida, a diversidade de olhares aqui apresentados sobre o conceito de competência trouxe à superfície a convergência e divergência de entendimentos, denunciando, desde logo, a panóplia de termos utilizados na sua definição e as diferenças de interpretação dos mesmos. No Quadro 1, podemos observar uma pequena síntese dos termos utilizados pelos autores aqui referenciados.

Do conjunto restrito de autores apresentados, ficamos com a noção de que os termos mais relacionados com a competência são o conhecimento, habilidades, situação, capacidade e desempenho, e que o conhecimento assume a primazia, logo seguido do termo habilidades. No trabalho de síntese para identificar os termos mais associados à competência, Weinert ${ }^{(50)}$ chegou aos seguintes termos: conhecimento (knowledge); qualificação (qualification); capacidade (ability; capacity), proficiência (proficiency) e habilidade (skill). Nesta síntese não figura o termo atitudes, que na pequena súmula por nós efectuada é apenas referenciado por Parry(34).

\section{Correlatos de competência}

Uma questão que importa equacionar reporta-se aos termos utilizados como sinónimos e ou correlatos de competência. Num esforço de descontaminação conceptual, Stoof, Martens, van Merriënboer e Bastiens ${ }^{(46)}$ procuraram analisar a oposição de termos como: competência vs. performance; competência vs. qualificação; competência vs. capacidade (capability and ability); competência vs. conhecimento, habilidades e atitudes; e competência vs. expertise.

$\mathrm{Na}$ questão da relação entre competência e desempenho [performance], apesar da implicação necessária entre os dois conceitos, eles não devem ser confundidos. De acordo com Gonzi, Hager e Athanasou(15): "Performance is what is directly observable, whereas competence is not directly observable, rather it is inferred from performance." (p. 6). Porém, os dois termos continuam teimosamente a ser utilizados de forma indiferenciada. Para tornar mais clara a distinção, Holmes (18) alega, a título de exemplo, que qualquer condutor competente, em determinadas circunstân- cias (mau tempo, situação de emergência, cansaço, álcool), pode ter um desempenho deficiente ou imprudente.

Competência e qualificação devem ser também distinguidas. A qualificação refere-se, de forma geral, a processos formais que conduzem à atribuição de um grau, diploma, certificado, ou reconhecimento de habilitação numa dada área ou função. Em muitas áreas, a qualificação é um requisito não apenas para aceder à profissão, mas também para aceder à competência na respectiva área. Porém, em muitas esferas da vida, a questão da qualificação não é chamada para julgar a questão da competência e, em contrapartida, noutros aspectos, pessoas com elevada qualificação não são necessariamente competentes ${ }^{(46)}$. Nos anos 1980s, no Reino Unido, foi introduzido um sistema de qualificação profissional - The National Vocational Qualifications (NVQ). Os críticos deste sistema sublinham a excessiva ênfase na avaliação de resultados em detrimento do processo de aprendizagem, a redução da competência à demonstração de capacidades e habilidades genericamente descritas(31).

Capacidade tem um uso bem mais generalizado do que competência e por isso talvez mais difícil de delimitar como conceito. Em língua inglesa, 'capability', por ser um termo menos corrente que 'ability', ou mesmo que 'capacity', poderia ser um melhor candidato a uma demarcação conceptual. Porém capability surge na literatura quer para definir competência (ex: A competency is a measurable human capability that is required for effective performance (25), quer como sinónimo de competência (ex: As such we shall regard the two terms as being sufficiently similar for the literature on (individual-level) competencies to be broadly applicable to the study of (individual-level) capabilities and vice versa) (23).

$\mathrm{Na}$ exploração do conceito de competência, os elementos conhecimento e habilidades surgem incorporados na generalidade das definições. Já as atitudes ora aparecem como elemento da competência, ora com um estatuto particular(26). Conhecimento e habilidades tendem a ser visíveis, logo mais susceptíveis de ensinar, de desenvolver com o treino, enquanto que as características da pessoa como o autoconceito, traços de personalidade e motivos estão escondidos, logo de difícil acesso e de mais 
difícil desenvolvimento. Apesar de o conhecimento ser um elemento chave da competência, ele não é suficiente para se ser competente(37), e portanto não se pode tomar o conhecimento pela competência. No que respeita às habilidades, o grau de sobreposição depende da abrangência dada aos termos. E habilidade (skill), mais ainda que competência, é um termo sujeito a definições muito diversas. Nas definições mais restritivas, habilidades são inequivocamente elementos da competência.

Porém, nas definições mais abrangentes de habilidades ou nas definições mais restritivas de competência, os termos podem vir a confundir-se.

Westera ${ }^{(51)}$ sustenta que o conceito de competências não tem qualquer significado para além da sua associação ao termo 'skills', afastando-se dos que pretendem conferir poder explicativo à competência, enquanto conceito que incorpora a aplicação efectiva do conhecimento especializado e das habilidades num contexto específico. Perrenoud(36) também não vê qualquer utilidade em distinguir competências de habilidades, distanciando-se daqueles que pretendem reservar o conceito de competências para as operações cognitivas de nível superior e relegar as habilidades para os níveis cognitivos inferiores.

A expertise aparece associada, de uma forma geral, a áreas de conhecimento e acção especializadas. O termo expertise remete para as ideias de elevada competência, elevada experiência e elevada eficiência no desempenho das tarefas. Quando aparecem relacionadas, a competência aparece como um grau abaixo da expertise, como por exemplo nos estádios de desenvolvimento profissional(4).

Um outro foco de confusão deriva do modo como se concebe a relação entre 'competência', conceito global, e 'competências', conceito sectorial. O termo competência como correlato de competências remete frequentemente para um entendimento analítico da competência, entendida como súmula de competências, passíveis de pré-especificação operacional e avaliação objectiva.

Stoof, Martens, van Merriënboer e Bastiens ${ }^{(46)}$ procuraram resolver o problema da definição de competência, não através de uma definição correcta universal de competência, mas pela construção de uma definição pragmaticamente viável e socialmen- te construída pelos sujeitos que a vão usar tendo por referência as pessoas, os objectivos e os contextos. Com este propósito estes autores, compararam a forma de entendimento da competência à forma de uma amiba, que se molda em função do equilíbrio de dois conjuntos de forças, as forças que se exercem de dentro para fora e as forças que se exercem de fora para dentro. As forças que se exercem de dentro para fora resultam da expressão particular dada a cada uma das dimensões da competência, isto é em que medida a competência é entendida aos longos dos eixos bidireccionais (1) característica pessoal versus característica da tarefa; (2) competência do indivíduo versus competência distribuída; (3) natureza geral versus natureza específica; (4) competência como nível versus níveis de competência; (5) ensinável versus não ensinável. Por outro lado, as forças que se exercem de fora para dentro têm a ver com os correlatos de competência e demais termos associados, cujas definições e definições das relações com o conceito de competência tendem a restringir ou a aumentar o âmbito do conceito.

O principal propósito deste estudo foi identificar o "campo nocional" que rodeia o conceito de competência, colocando em evidência a diversidade de termos que os profissionais do desporto associam à "ideia" de competência, acrescido da identificação do "núcleo" de características que estes associam ao profissional competente, na procura de indicações que contribuam para o mapeamento do conceito de competência, aplicável ao seu campo de intervenção profissional.

Ao explorarmos os termos que os profissionais do desporto associam à competência tentámos percepcionar a existência de aspectos convergentes e divergentes em quatro áreas de intervenção do profissional do desporto (Educação Física, treino, fitness e actividade física adaptada). A nossa opção é reforçada por autores como Sandberg(38) que considera que a competência deve ser entendida na relação íntima que o trabalhador estabelece com o trabalho que executa, trabalhador e trabalho são consideradas uma entidade única. A exploração das características teve como principal objectivo obter informação complementar que contribua para uma ideia mais clarificada da ideia de competência do profissional do desporto. 


\section{Material e métodos \\ Universo profissional e fraccionamento da amostra}

Tomando como referência genérica, a delimitação estabelecida no projecto AHESIS $^{3}$ circunscrevemos o âmbito do nosso estudo aos contextos de ensino e treino, dentro e fora do sistema escolar, ficando excluídas as áreas ocupacionais ditas não-pedagógicas, como a gestão, o comércio e a comunicação social, entre outros. Assim sendo foram consideradas quatro áreas de ocupação profissional no âmbito do desporto: Educação Física, Treino Desportivo, Fitness e Actividade Física Adapatda.

A constituição da amostra não obedeceu rigorosamente a métodos de amostragem formais, mas cumpriu o critério de selecção de amostras significativas para estudos de natureza qualitativa, estratégia referida como admissível em amostras inferiores a 100 $\operatorname{casos}^{(17)}$. A amostra utilizada, não sendo representativa do universo profissional total, tem uma dimensão suficientemente grande (120), que se enquadra nas exigências de um estudo de natureza qualitativa, permitindo assim suportar as análises dos dados previstas. Cada área profissional é representada por 30 sujeitos, 14 do sexo feminino e 16 do sexo masculino. As idades dos respondentes estão compreendidas entre os 23 e os 58 anos, com médias de idades relativamente similares entre os grupos, mas com valores de dispersão muito diferentes (professores de $E F-39,03 \pm 0,51$; treinadores - 38,30 $\pm 6,91$; professores de Fitness - 32,57 $\pm 8,25$; professores de Actividade Física Adaptada - 35,50 $\pm 10,18$ ), parecendo reflectir a maior ou menor estabilidade e longevidade de cada área ocupacional.

Relativamente às habilitações académicas, apenas nos grupos de treinadores e professores de fitness existem profissionais que não possuem formação superior específica, com uma expressão muito similar em ambos os grupos, cerca de $30 \%$.

O estatuto de ex-praticante desportivo é uma realidade na maioria dos profissionais entrevistados, assumindo expressão mais elevada no grupo dos treinadores (83,3\% foram ex-atletas), surgindo logo de seguida o grupo de Fitness, com $80 \%$ de ex-praticantes. No que respeita à vinculação profissional, importa referir que grande percentagem destes profissionais se pauta pela acumulação de funções. Ainda assim, nas áreas do fitness e do treino a tendência para a exclusividade já seja mais notória $(46,6 \%$ e $30 \%$ respectivamente).

\section{Procedimentos de recolha}

Os dados obtidos resultaram de uma entrevista semi-estruturada, constituída por seis questões abertas. Todos os sujeitos foram entrevistados pelo mesmo entrevistador, em ambiente calmo e sem a interferência de terceiros. Foram entrevistados sujeitos pertencentes a quatro áreas do campo do profissional do desporto: professores de Educação Física; professores de actividade física adaptada, professores de fitness e treinadores desportivos.

Neste estudo apenas duas questões da entrevista são objecto de análise:

Q1 - "Quando pensa em competência, quais os termos que imediatamente lhe associa?”.

Q3 - "Quais as principais características que associa a um professor 4 competente?"

\section{Procedimentos de análise}

As respostas foram analisadas por recurso aos procedimentos de análise de conteúdo. Iniciámos o processo efectuando a transcrição integral das entrevistas, para posteriormente sujeitar as respostas a um processo iterativo de classificação. Os procedimentos de análise das duas questões foram similares, na primeira questão utilizaram-se os seguintes passos analíticos:

1. identificação, anotação e contagem de todos os termos referenciados pelos respondentes;

2. condensação dos termos identificados, por recurso à similitude semântica por forma a reduzir a dispersão dos termos originais;

3. hierarquização dos termos mais referenciados, após condensação;

4. ordenação dos termos mencionados em função da ordem de referência;

5. representação gráfica dos termos mais valorizados resultante da agregação da hierarquia e da ordem de referência, de acordo com os seguintes critérios:

i. consideraram-se os termos referenciados nos três primeiros lugares da hierarquia acrescidos, dos termos referenciados mais vezes em primeiro lugar, até ao mínimo de duas referências.

ii. Acréscimo do número de referências, dos termos presentes nos três primeiros lugares da hierarquia. 
O acréscimo do número de referências foi feito em função do número de vezes que o termo foi referenciado em primeiro lugar, a escala utilizada foi a seguinte: termo referenciado $\leq 2-+1$ referência; entre $3 e$ $5-+2$ referências; $>5-+3$ referências.

$\mathrm{Na}$ questão 3, à semelhança da questão anterior, foram seguidos os seguintes passos analíticos:

1. identificação, anotação e contagem das características associadas ao profissional competente;

2. condensação das características referenciadas, por recurso à similitude semântica por forma a reduzir a dispersão do número de termos originais;

3. hierarquização das características mais referenciadas, após condensação;

4. agregação das características da mesma natureza tomando como pontos de referência as componentes da competência referenciadas por Stoof, Martens, van Merriënboer e Bastiens (46) como amplamente aceites pela generalidade dos autores - conhecimentos, habilidades e atitudes - e as dimensões de avaliação da aptidão profissional individual(13) - dimensão intelectual, dimensão técnica, dimensão moral e dimensão relacional.

\section{Apresentação e discussão dos resultados Termos associados à competência}

$\mathrm{Na}$ inquirição dos termos associados ao conceito de competência, podemos constatar que o número de termos mencionados, quer pela totalidade da amostra, quer por cada grupo de ocupação profissional, é muito elevado. Os respondentes referiram um total de 476 termos, dos quais 327 são diferentes. O número total de termos mencionados por cada grupo de ocupação profissional assume o valor mais expressivo nos professores de actividade fisica adaptada (131) e a menor expressão nos professores de fitness (101). Mesmo após a condensação dos termos, por recurso à proximidade semântica, ainda se obtêm 272 termos, número manifestamente elevado (Quadro 2).

Quadro 2. Número total, parcial e após "condensação" dos termos em função da área ocupacional

\begin{tabular}{lccccc}
\hline No $^{0}$ de termos & $\begin{array}{c}\text { Educação } \\
\text { Física }\end{array}$ & Treinador & Fitness & $\begin{array}{c}\text { Actividade } \\
\text { Física } \\
\text { Adaptada }\end{array}$ \\
\hline total & 128 & 116 & 101 & 131 & 476 \\
diferentes & 90 & 80 & 68 & 89 & 327 \\
condensados & 69 & 71 & 59 & 73 & 272 \\
\hline
\end{tabular}

Um primeiro aspecto que sobressai destes resultados é a abrangência, a diversidade e dispersão presente em todos os grupos. Mesmo o grupo dos professores de fitness, que apresenta o menor valor (68), expressa claramente a falta de consenso, que tanto pode ser reflexo de uma falta de esclarecimento acerca do que é a competência, como da ausência do hábito de reflectir acerca de questões desta natureza. Batista, Graça e Matos(3), num estudo preliminar, com uma amostra de 90 sujeitos, obtiveram resultados similares, encontrando um total de 157 termos diferentes. Estes resultados corroboram os dados evidenciados pela literatura, que revelam uma extensa listagem de termos associados à competência. Neste momento, continuamos a assistir, nos diversos campos profissionais, não só a uma utilização de termos diferentes com significados similares, mas também à utilização do mesmo termo para representar conceitos diferentes. Autores como Boak ${ }^{(5)}$; Woodruffe ${ }^{(55)}$; Tate ${ }^{(47)}$; Winterton(54) referem que as variadíssimas tentativas de estabelecer uma terminologia coerente tiveram até agora muito pouco sucesso. Stoof ${ }^{(45)}$ vem reforçar esta ideia ao considerar que um dos principais problemas que se colocam nos estudos da competência é a falta de clarificação do conceito, acrescida da dificuldade em distinguir o conceito de competência de outros termos relacionados. No seu estudo, os problemas de natureza conceptual foram apontados por $64 \%$ dos respondentes envolvidos numa equipa de construção de um mapa de competência.

Hierarquia dos termos mencionados após "condensação" Na sequência da condensação dos termos mencionados, passamos ao segundo patamar de análise, hierarquizando os termos mais referidos. Considerando apenas os termos referenciados nos quatro primeiros postos, um aspecto ganha logo relevo, o número de referências de cada termo é muito baixo - conhecimento (38); profissionalismo (17); empenhamento e responsabilidade (12); capacidade (8); formação, pontualidade e assiduidade (6); ... - face ao número total de termos (476) e tendo em conta que foram 130 inquiridos, sem qualquer restrição do número de termos que podiam mencionar.

Quando observamos cada grupo individualmente, deparamo-nos com o mesmo cenário. $\mathrm{O}$ termo conhe- 


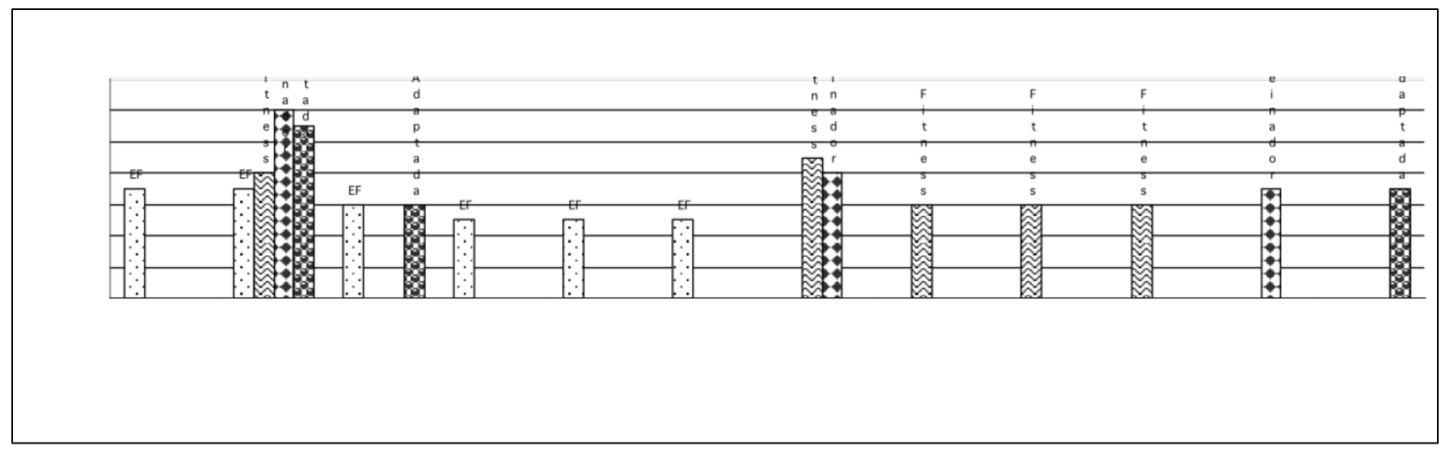

Figura 1. Expressão dos termos por área ocupacional (3 primeiros postos)

cimento ocupa o lugar cimeiro entre os termos mencionados. No grupo de treinadores, o conhecimento tem a expressão máxima (12 menções), decrescendo nos restantes grupos, para 11 nos professores de actividade física adaptada e 7 nos professores de $E F$, repartindo, neste caso, o lugar com o termo domínio. No grupo de fitness, o termo que recolhe mais referências é o profissionalismo, mas apenas com 9 menções (Figura 1). Apesar da pouca expressão da primazia do termo conhecimento, este surge como o termo mais referenciado, vindo de encontro à pequena síntese que elaborámos dos termos empregues nas definições de competência, em que o conhecimento aparecia na generalidade das definições, e das sínteses de autores como Mirabile(29) e Weinert(50), sobre os compósitos presentes no conceito de competência. Esta evidência reitera a generalidade dos estudos ao nível da formação, particularmente da formação de professores, em que o conhecimento é referenciado como elemento base da competência(e.g. $(12,16,42)$. Todavia, Perrenoud(37) não deixa de alertar que, apesar de essencial, o conhecimento não é suficiente para se ser competente, pois é necessário saber utilizá-lo. Noutras esferas, nomeadamente na pesquisa organizacional, desde os modelos de competência iniciais, como o de Boyatzis(6), o conhecimento é considerado um elemento central, com um impacto profundo nos vários níveis de competências 5 . $\mathrm{O}$ profissionalismo surge nos professores de fitness e no treinador com uma expressão similar (diferença de uma menção) no entanto nos outros dois grupos o termo não ocupa um lugar de destaque nesta hierar- quia, sendo apenas objecto de duas referências em cada um dos grupos.

A experiência é o terceiro termo mais mencionado pelos treinadores, não sendo referido uma única vez nos restantes grupos, excepto no grupo de fitness em que é referenciado uma vez. Será que este facto resulta de os treinadores possuírem uma visão mais interpretativa da competência, em que a experiência é um elemento valorizado ou simplesmente resulta da realidade que rodeia a profissão de treinador, que ainda hoje continua a ser "povoada" por ex-atletas e "curiosos" sem formações adequadas e muito menos formações superiores específicas, cuja tendência é valorizar a sua experiência no terreno como ex-atletas e como treinadores.

Podemos pensar que os resultados indiciam uma ideia de competência situada numa orientação interpretativa próxima de autores como Velve ${ }^{(49)}$, que considera o contexto em que cada pessoa trabalha e a experiência do trabalhador componentes da competência, e de Sandberg( ${ }^{(39)}$, que coloca ênfase na experiência na forma como interpreta a competência; ou considerar simplesmente que a explicação se relaciona mais com a realidade da profissão.

Relembremos que na amostra apenas $23,3 \%$ dos treinadores não tem formação superior específica. Nos grupos de professores de educação física e de actividade física adaptada, o termo responsabilidade ocupa o terceiro lugar da hierarquia, e no grupo de professores de fitness, apesar de não ser este o termo referido, surgem dois termos - pontualidade e assiduidade que se inserem no mesmo registo, podemos até 
dizer numa mesma dimensão - ética profissional. Importa ainda sublinhar que a generalidade dos termos referidos é de carácter marcadamente ético A importância atribuída às questões da ética profissional e pessoal é notória (ex. profissionalismo, responsabilidade, pontualidade, assiduidade, trabalho, disciplina, honestidade, seriedade, atitude). Esta ideia vem ao encontro da generalidade das conceptualizações de competência que consideram que o elemento unificador do conceito de competência é a sua íntima ligação ao exercício de uma profissão. Esta ligação já em 1930 era referenciada na Larousse Comercial e assumida por Gilbert e Parlier(14) quando referiam que a competência se reporta ao domínio de uma actividade profissional. Meignant ${ }^{(28)}$ vem reforçar esta ideia, quando refere que "a competência reconhece-se em situação de trabalho" que, por sua vez, se rege por um código de normas e valores. Outro aspecto que vem dar corpo a esta ideia é o facto, de a generalidade dos modelos de competência englobarem as questões éticas sob as mais diversas designações (e.g. traços ${ }^{(43)}$; atitudes(51); ética, valores (7); moral(13)).

Complementarmente, e neste registo, acerca das questões atitudinais e dos valores, Matos(26), baseando-se em autores como Ecke(11) e Flach(12), refere que a atitude não deve ser considerada como um elemento da competência, mas sim um atributo determinante da competência.

O termo gosto, associado a aspectos motivacionais, assume um lugar de destaque no grupo de actividade física adaptada (segundo lugar), reforçado com mais dois termos da mesma natureza, que surgem com duas menções cada (vontade e motivação). Nos restantes grupos, a sua expressão é menor e diferenciada, nos treinadores surge em quarto lugar, com três menções, e no grupo de fitness em quinto com apenas duas menções. Os professores de EF não mencionam o termo gostar mas referem outros relacionados com aspectos motivacionais, mas apenas com uma menção cada um (interesse e desafio). Autores como Willis, Dubin(53) na sua descrição de competência referem a motivação como um factor importante da competência, assim como Cheetham e Chivers $(7,8)$ que incorporam no modelo de competência profissional que desenvolveram a motivação. $\mathrm{O}$ factor motivacional tende a ser incluído em descrições de competência amplas, designadas por
Kouwenhoven (21) de descrições de competência mais elaboradas. O termo saber fazer no grupo dos professores de EF ocupa o terceiro lugar, nos treinadores é omisso e nos professores de actividade física adaptada de fitness é apenas referenciado uma vez. Em termos de síntese, importa referir que o conhecimento é o único termo que é mencionado pelos quatro grupos, nos três primeiros lugares da hierarquia. e o profissionalismo e responsabilidade (ou termos da mesma natureza como pontualidade e assiduidade) são termos mencionados nos lugares cimeiros (3 primeiros). Batista, Graça e Matos(3) num estudo piloto encontraram resultados muito semelhantes, pois os termos conhecimento e profissionalismo surgiram nos três primeiros lugares dos termos mais mencionados. O grupo de fitness evidencia uma tendência à valorização dos aspectos éticos (e.g. profissionalismo, assiduidade, pontualidade, responsabilidade) e os treinadores são os únicos a referir o termo experiência.

Relativamente aos profissionais que trabalham com populações especiais estes evidenciam uma concepção mais relacionada com questões de carácter afectivo, denunciam uma componente de envolvimento pessoal muito marcada. Por último os professores de Educação Física valorizam o saber fazer, denunciando uma concepção de competência muito associada à prática, a aspectos de natureza funcional.

Tomando com referência a ideia de Stoof, Martens, van Merriënboer e Bastiens(46), que referem que alguns termos são dimensões da competência e outros se situam numa esfera de influência mais ou menos próxima, os resultados induzem-nos a considerar os termos conhecimento e profissionalismo como elementos passíveis de serem considerados constituintes da competência, ou pelo menos elementos que se situam numa esfera próxima de influência do campo conceptual da competência.

Relativamente à distribuição dos termos é notória uma acentuação de termos relacionados com o conhecimento e com as questões éticas. Importa ainda referir que independentemente deste perfil geral que trespassa as quatro áreas profissionais, são visíveis diferentes acentuações de determinados termos em função da área profissional. A tradição que tende a ligar o profissional de EF à prática é bem visível nos resultados encontrados, o saber fazer é o terceiro termo mais mencionado. A perspectiva funcionalista 
Quadro 3. Ordem de referência dos termos em função da área ocupacional

\begin{tabular}{|c|c|c|c|c|}
\hline & Educação Física & Treino & Fitness & $\begin{array}{l}\text { Actividade } \\
\text { Física Adaptada }\end{array}$ \\
\hline $1^{\circ}$ lugar & $\begin{array}{l}\text { qualidade (3) } \\
\text { responsabilidade (3) } \\
\text { domínio (2) } \\
\text { conhecimento (2) } \\
\text { capacidade (2) }\end{array}$ & $\begin{array}{l}\text { conhecimento (9) } \\
\text { profissionalismo [5] } \\
\text { experiência; organização (2) }\end{array}$ & $\begin{array}{l}\text { profissionalismo (5) } \\
\text { assiduidade (4) } \\
\text { formação (3) } \\
\text { responsabilidade (3) } \\
\text { conhecimento (3) }\end{array}$ & $\begin{array}{l}\text { conhecimento (5) } \\
\text { responsabilidade (3) } \\
\text { disponibilidade (2) }\end{array}$ \\
\hline $2^{\circ}$ lugar & $\begin{array}{l}\text { empenhamento (2) } \\
\text { método (2) } \\
\text { trabalho (2) }\end{array}$ & $\begin{array}{l}\text { experiência (4) } \\
\text { conhecimento (2) } \\
\text { seriedade (2) }\end{array}$ & $\begin{array}{l}\text { pontualidade (5) } \\
\text { formação (3) } \\
\text { profissionalismo (2) } \\
\text { planeamento (2) }\end{array}$ & $\begin{array}{l}\text { empenhamento (3) } \\
\text { assiduidade (2) }\end{array}$ \\
\hline $3^{\circ}$ lugar & $\begin{array}{l}\text { Não aparece nenhum termo } \\
\text { com mais de uma menção }\end{array}$ & $\begin{array}{l}\text { sucesso }(2) \\
\text { gosto }(2)\end{array}$ & $\begin{array}{l}\text { simpatia (3) } \\
\text { dedicação [2] } \\
\text { assiduidade (2) } \\
\text { disponibilidade (2) } \\
\text { profissionalismo (2) }\end{array}$ & $\begin{array}{l}\text { disciplina (3) } \\
\text { conhecimento (2) }\end{array}$ \\
\hline
\end{tabular}

de competência ganha "corpo" nos profissionais de EF. Na área dos profissionais que trabalham com populações especiais a componente afectiva, muito relacionada com aspectos motivacionais, ganham relevo termos como: gostar, vontade, motivação. Nos professores de fitness a marca diferenciadora situa-se nos termos referidos relacionados com a personalidade, tais como: simpatia, paciência, carisma, simplicidade, entre outros. Nestas duas áreas a perspectiva personalista parece estar presente. Os termos mencionados pelos treinadores ganham um grande peso na componente associada aos resultados como se pode constatar pela referência a termos como: sucesso, qualidade, eficiência, resultados, rendimento, perfeição, entre outros (perfazendo um total de 18 termos) e a experiência é muito valorizada, ocupando o segundo lugar da hierarquia com sete referências. Nesta área parecem associar-se duas perspectivas, uma behaviorista, relacionada com os resultados, e outra mais interpretativa relacionada com a experiência.

\section{Ordem de referência dos termos}

Ao nos centrarmos na ordem pela qual os termos foram referidos, constatámos que as sequências de termos, tal como o número de termos, são muito díspares, não sobressaindo em nenhuma área profissional, qualquer tipo de padrão. O número de termos mencionados por cada respondente varia entre um (2 treinadores e 1 professor de EF) e dez ( 2 pro- fessores de EF), mas a grande maioria refere 3 a 4 termos (cerca de $71 \%$ ).

Ao analisarmos os termos que foram mais vezes mencionados em primeiro, segundo e terceiro lugares (Quadro 4) e tendo em conta os termos mais mencionados (Quadro 3) verificámos que, dentro de cada área, existe uma associação entre a ordem de referência dos termos e os termos mais mencionados. O termos referidos mais vezes em primeiro e segundo lugares (Quadro 4), à excepção do grupo de professores de EF, são detentores dos primeiros lugares da hierarquia dos termos mais referidos.

Pela observação dos dados podemos verificar que, no grupo de fitness, os termos mencionados mais vezes em primeiro lugar são o profissionalismo (5 menções), seguido da assiduidade (4 menções) e de três termos com o mesmo número de referências (3 menções): formação, conhecimento e responsabilidade. Em segundo lugar, e com a mesma expressão do termo profissionalismo, que é referido 5 vezes em primeiro, surge a pontualidade, seguida da formação (3 menções). O terceiro posto é ocupado pelo termo simpatia (3 menções).

O termo mais vezes referido em primeiro lugar pelos professores de populações especiais é o conhecimento (5 menções) seguido da responsabilidade (3 menções) e disponibilidade (2 menções). De salientar que o termo gosto apesar de ser o segundo termo mais mencionado por este grupo (7 menções) apenas é referido 


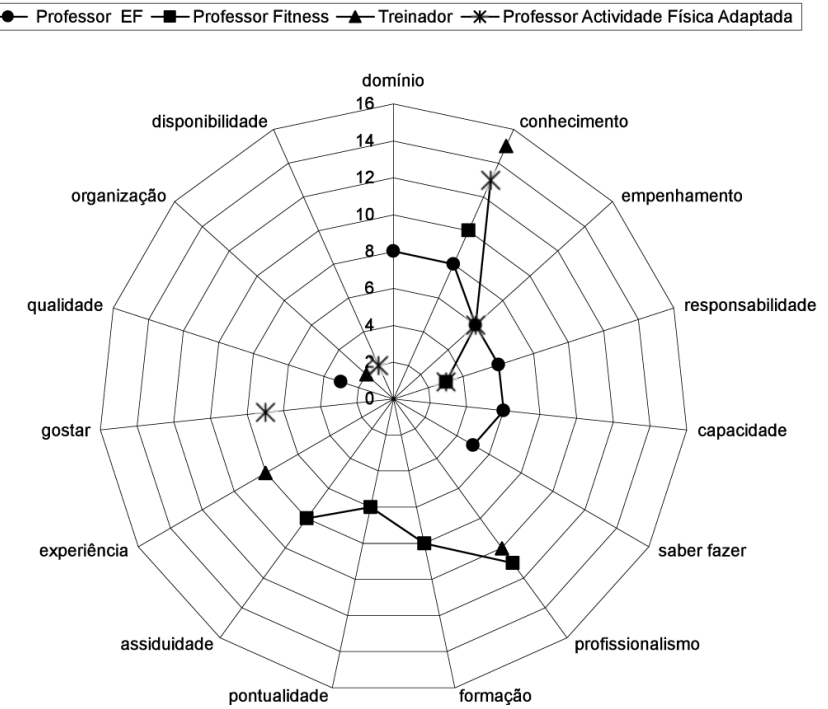

Figura 2. Representação da valorização dos termos agregação da hierarquia com a ordem de referência uma vez em $3^{\circ}$ lugar e as restantes 6 referências aparecem nas quarta e quinta posições.

Nos treinadores, os termos mais referidos em primeiro lugar são o conhecimento (que foi o termo referido mais vezes), seguido do profissionalismo (5 menções), experiência e organização (ambos com 2 menções). Em segundo lugar, surge a experiência (4 menções) e a seriedade (2 menções), e em terceiro surgem os termos sucesso e gosto, com apenas duas menções cada. No grupo dos professores de EF, o panorama difere dos restantes: os termos referidos mais vezes em primeiro lugar são a responsabilidade e a qualidade (ambos com 3 menções), e o conhecimento e o domínio, que na hierarquia dos termos (Quadro 3) são os termos mais referidos por este grupo (7 menções cada um). Porém, só foram referidos duas vezes em primeiro lugar, juntamente com o termo capacidade. As restantes menções surgem apenas após o terceiro termo mais mencionado. O segundo lugar é ocupado por três termos - empenhamento, método e trabalho - com duas menções cada.

Tomando como referência a ideia de Stoof, Martens, van Merriënboer e Bastiens (46), procurámos agregar a informação resultante da hierarquia e da ordem de referência dos termos, chegando a uma representação da valorização que é dada por cada área profissional aos termos mais mencionados (Figura 2) dentre os termos representados que ocupam os três primeiros lugares da hierarquia acrescidos dos que foram referidos mais vezes em primeiro lugar.

Ao observarmos a Figura 2, verificámos que não existe convergência nos termos que são mencionados pelas quatro áreas profissionais. Interpretando os dados por recurso à perspectiva de Stoof, Martens, van Merriënboer e Bastiens(46) verificámos que o termo que se encontra numa órbita de maior proximidade com o "núcleo" da competência é o conhecimento, isto apesar de no fitness o profissionalismo estar um pouco mais perto, com uma diferença mínima (Figura 3).

Ao analisarmos a proximidade dos termos ao núcleo da competência em cada grupo, constatámos que os termos estão ordenados da seguinte forma:

Treinador - conhecimento, profissionalismo, experiência e, por último, organização.

Professor de EF - conhecimento e domínio com a mesma proximidade, seguido de empenhamento, capacidade e responsabilidade, depois saber fazer e, por último, qualidade.

Professores de actividade física adaptada - conhecimento, gostar, empenhamento, depois responsabilidade e, por último, disponibilidade.

Professores de fitness - profissionalismo, conhecimento, formação e assiduidade, depois pontualidade e, por último, responsabilidade.

Além do termo conhecimento, que surge como um termo próximo do núcleo da competência em todas as áreas profissionais, os restantes termos colocamse em diferentes zonas de proximidade, e os pontos de convergência não são muitos. De referenciar apenas o profissionalismo, que surge em três grupos, mais próximo do núcleo nos professores de EF, seguido dos professores de populações especiais e depois os de fitness. Ao considerarmos a síntese de Weinert(50) sobre os "compósitos" da competência e os resultados por nós encontrados na análise das definições 
Figura 3.

Representação

dos termos em

função da sua

proximidade ao

"núcleo" da

competência-

geral e por área

ocupacional
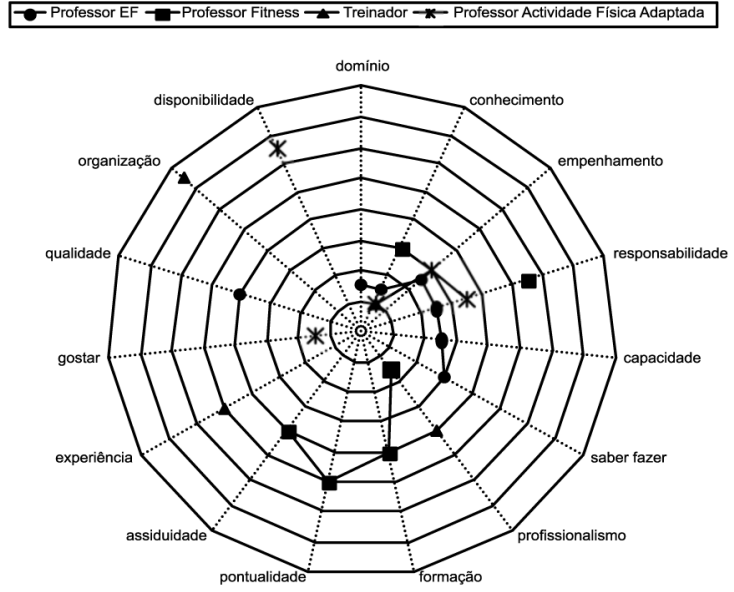
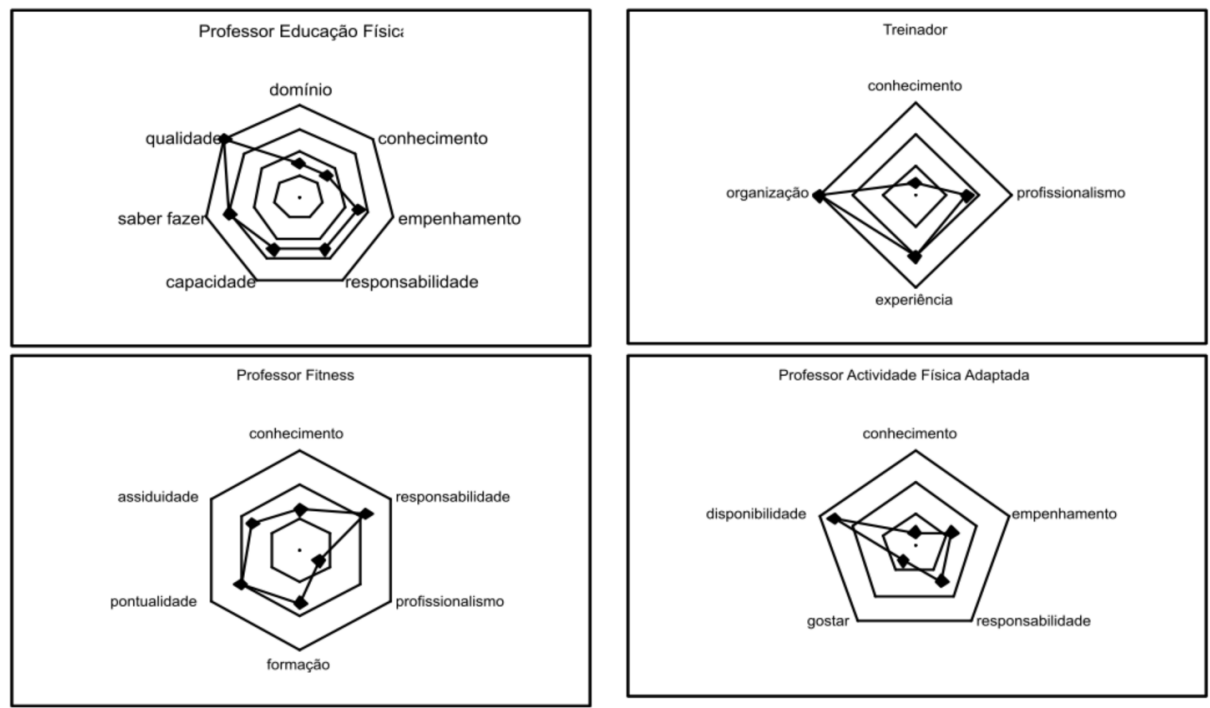

apresentadas neste trabalho, o facto de o conhecimento surgir como um termo de grande proximidade ao núcleo de competência adere à ideia generalizada de que o conhecimento é fundamental à competência. Quanto ao profissionalismo, este é referenciado por Parente (33) como sinónimo de competência. O termo capacidade é também um termo indicado como um elemento que faz parte da competência ${ }^{(50)}$, apenas surge no grupo dos professores de EF. O termo experiência ao ser referenciado pelos treinadores, colocan- do-o em terceiro lugar na hierarquia de proximidade ao núcleo da competência, vem de encontro a perspectivas que colocam ênfase na experiência, considerando-a fundamental à competência $(39,49)$. Os restantes termos acabam por se distanciar destas sínteses, apesar de alguns termos serem de natureza semelhante (ex: habilidade e saber fazer). Os professores de $E F$ são o grupo que mais termos refere na órbita próxima do núcleo da competência (com 7 termos, sendo alguns da mesma natureza) e o treinador o 
Quadro 4. Características associadas a um profissional competente em função da área ocupacional.

\begin{tabular}{|c|c|c|}
\hline & Prof. EF (EF) & Treinador $[\mathrm{T}]$ \\
\hline HIERARQUIA & $\begin{array}{l}\text { - relação com os alunos; } \\
\text { assíduo; pontual; empe- } \\
\text { nhado (5) } \\
\text { - sabe planear; domina a } \\
\text { matéria; formação; comu- } \\
\text { nicar; conhecimento; adap- } \\
\text { tação; atitude (3) }\end{array}$ & $\begin{array}{l}\text { - liderança (9) } \\
\text { - pontualidade (5) } \\
\text { - postura pedagógica; } \\
\text { resultados; perfeccio- } \\
\text { nista; conhecimento (4) }\end{array}$ \\
\hline $\begin{array}{l}\text { Características } \\
\text { pessoais } \\
\text { EF }-n=20 \\
T-n=34 \\
F-n=15 \\
\text { AFA }-n=17\end{array}$ & $\begin{array}{l}\text { afável; não rígido; flexível; } \\
\text { sentido humor; autoridade; } \\
\text { compreensivo; acertivo; } \\
\text { amigo; versátil; interventi- } \\
\text { vo; espírito iniciativa; sen- } \\
\text { sível; prestável; respeita- } \\
\text { dor; sabe impor-se; demo- } \\
\text { crático }\end{array}$ & $\begin{array}{l}\text { ambicioso; perfeccionista; } \\
\text { espírito de humor; perso- } \\
\text { nalidade forte; liderança; } \\
\text { curioso; dinâmico; espíri- } \\
\text { to combatividade; espírito } \\
\text { de sacrifício; autoritário; } \\
\text { convictos; seguro; flexível; } \\
\text { tolerante; perseverança; } \\
\text { compreensivo; equilibra- } \\
\text { do; inteligente; persuasi- } \\
\text { vo; afectividade; consis- } \\
\text { tente; parte psicológica }\end{array}$ \\
\hline
\end{tabular}

Prof. Fitness (F)
- simpático (4)
- pontual; conheci-
mento (3)
- actualizar-se; boa re-
lação; boa apresenta-
ção; profissional; lidar
bem com os clientes (2)

paciência; alegre;

divertido; simpático;

boa disposição; boa

pessoa; humilde; moti-

vador; animador; incen-

tivador

Prof. Act. Física Adaptada (AFA)

- motivar [6]

- disponibilidade;

conhecimento (5)

- sensibilidade (4)

afectuoso; atencioso; atento; paciente; afável; sensibilidade; tolerante; persistência; alegre; curiosidade
Características relaciona-se bem com os relação com os atletas;

relacionais

$\mathrm{EF}-\mathrm{n}=11$

$T-\mathrm{n}=13$

$\mathrm{F}-\mathrm{n}=10$

AFA $-n=22$ alunos; boa relação professor-aluno; boa empatia; relação social afectiva boa; boa relação com os alunos; promover bom clima de aula; estabelecer boas relações; bom clima de aprendizagem; interagir com os alunos conseguir lidar com as pessoas; boa relação com os alunos; jeito para lidar com os alunos; servir o cliente; conseguir lidar com as pessoas; empatia; saber ouvir os colegas; partilhar saber lidar com as pessoas; trazer alegria para a aula ; parte social; ter tempo para dialogar com os idosos; consegue falar facilmente; interagir com eles; bom senso na relação; empatia; receptivo; saber ouvir as pessoas; ligação mais próxima às pessoas; respeitar os alunos; interagir com eles; compreender estas populações; saber receber; dominar afectivamente; boa relação humana; aceitar os alunos integrar-se bem; sociável

ética
profissional
EF $-n=22$
$T-n=32$
$F-n=15$
$A F A-n=25$

pontual; assíduo; organiza- organizado; rigoroso; pondo; rigoroso; metódico; pro- tualidade; presença a fissional; cumpre regras; responsável tempo e horas; profissio nalismo; responsável; ter regras; aplicar valores; acreditar e lutar por deter-
minados valores; trabaIhador; empenhado; dedicado; interessado; preocupação com o trabalho

EF-n=15 formação pontual; assíduo; organiza- conhecimento na área; bom

$T-n=24$ pontual; assiduo; organiza-
do; rigoroso; metódico; pro-

$\mathrm{F}-\mathrm{n}=10$ TOTAL fissional; cumpre regras;

AFA- $n=16 \quad$ EF- $n=26$ responsável

$\mathrm{T}-\mathrm{n}=28$

Conheci- $\quad F-n=20$

mento AFA- $n=22$

$E F-n=11$

$\mathrm{T}-\mathrm{n}=4$

$\mathrm{F}-\mathrm{n}=10$

AFA $n=6$ profissional; profissionalismo; atitude perante a profissão; rigoroso; responsável; pontual; assíduo; cumprir horários; chegar a horas

dedicado; interessado; disponibilidade; profissionalismo; rigoroso; responsabilidade; exigente consigo; assiduidade; pontualidade; empenho; dar-se à causa; esforçar-se muito; entregar-se àquilo que está a fazer

Formação; bem formado no assunto; conhecimento; boa formação técnica; sabe de anatomia e fisiologia

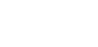

conhecimento; saber o que se está a dar; saber de deficiência, modalidade e psicologia; formação; conhecimentos teóricos; competência científica; domina a área de intervenção; bons conhecimentos científicos e pedagógicos; conhecimentos científicos nível teórico; domina conhecimento; conhecimento geral e específico; domina as areas técnicas; conhecimento da modalidade; formação académ ca; conhecimento do planeamento; formação de base; conhecer o jogo; bons conceitos tácticos e estratégias; conhecer o treino; conhecer os princípios do treino; conhecimento do que é o desporto e a prática desportiva; ter conhecimento dos atletas; competência técnica e científica; ter conceito de jogo; conhecedor do que faz 
Prof. EF $[E F]$

Treinador $[\mathrm{T}]$

Prof. Fitness [F]

Prof. Act. Física Adaptada (AFA)

formação actualizar-se; curiosidade permanentemente insa-

contínua para aprender; tem avidez tisfeito; adquirir formade saber; renovar o ensino; ção; estar atento estudar todos os dias; capacidade de procurar e inovar; cultivar-se; vontade de mudança necessidade de fazer melhor; inconformismo

\begin{tabular}{|c|c|c|c|c|c|}
\hline \multirow[t]{3}{*}{$\begin{array}{l}\text { habilidades } \\
\text { /dimensão } \\
\text { técnica } \\
\text { EF-n=17 } \\
T-n=29 \\
F-n=14 \\
\text { AFA- } n=23\end{array}$} & $\begin{array}{l}\text { prepa- } \\
\text { ração }\end{array}$ & $\begin{array}{l}\text { saber retirar o que é essen- } \\
\text { cial da matéria, o que os } \\
\text { alunos têm de dominar }\end{array}$ & $\begin{array}{l}\text { qualidade de preparação } \\
\text { dos treinos e época; saber } \\
\text { planear; preparar treinos; } \\
\text { trabalhar nas áreas da } \\
\text { observação; preparação } \\
\text { de tudo para que corra o } \\
\text { melhor possível; trabalha- } \\
\text { dor nos planeamentos }\end{array}$ & $\begin{array}{l}\text { colocar objectivos cla- } \\
\text { ros; saber avaliar e pla- } \\
\text { near }\end{array}$ & $\begin{array}{l}\text { estabelecer metas e objecti- } \\
\text { vos; exercícios adaptados aos } \\
\text { alunos }\end{array}$ \\
\hline & $\begin{array}{l}\text { realiza- } \\
\text { ção }\end{array}$ & $\begin{array}{l}\text { motivar os alunos para a } \\
\text { aula; promover e motivar } \\
\text { para a aprendizagem; criar } \\
\text { clima que leve os alunos a } \\
\text { gostarem das aulas; preo- } \\
\text { cupação em criar pessoas } \\
\text { emocionalmente saudá- } \\
\text { veis; chegar a todos os alu- } \\
\text { nos e ao aluno; fazê-lo } \\
\text { aprender; arranjar estraté- } \\
\text { gias para chegar ao aluno; } \\
\text { soluções para dar o que os } \\
\text { alunos precisam; chegar ao } \\
\text { nível dos alunos; misturar } \\
\text { intuição com técnicas; } \\
\text { capacidade de tocar nos } \\
\text { pontos fundamentais aos } \\
\text { alunos; trabalho dirigido } \\
\text { aos alunos; parte pedagó- } \\
\text { gica; sabe concretizar; con- } \\
\text { segue transmitir; passar a } \\
\text { informação de forma con- } \\
\text { creta }\end{array}$ & $\begin{array}{l}\text { sintonizar área da prepa- } \\
\text { ração física ; procurar } \\
\text { alcançar os objectivos; } \\
\text { saber explicar e transmi- } \\
\text { tir; consegue transmitir } \\
\text { ideias; transmitir ao grupo } \\
\text { a realidade; aneira como } \\
\text { se ensina; saber ensinar; } \\
\text { saber estar no treino } \\
\text { dando feedbacks; durante } \\
\text { o treino corrigindo; capa- } \\
\text { cidade de tomar decisões }\end{array}$ & $\begin{array}{l}\text { aplicar conhecimentos; } \\
\text { bom nível técnico; não } \\
\text { deixar fazer o que pre- } \\
\text { judica; saber exprimir o } \\
\text { que sabe; sabe ler o } \\
\text { corpo o movimento; } \\
\text { observação corporal; } \\
\text { não exagerar nas car- } \\
\text { gas; não mandar fazer } \\
\text { aquilo que não sabe } \\
\text { controlar bem os alu- } \\
\text { nos; não inventar; con- } \\
\text { seguir fazer o que } \\
\text { manda fazer }\end{array}$ & $\begin{array}{l}\text { ir ao encontro deles; manter o } \\
\text { interesse deles; capacidade de } \\
\text { motivar; não procurar ir muito } \\
\text { longe; adaptar de acordo com } \\
\text { os idosos; ter cuidado com o } \\
\text { que faz; capacidade de adapta- } \\
\text { ção; saber transmitir; flexibili- } \\
\text { zação perante as turmas; } \\
\text { capacidade de moldar-se às } \\
\text { situações; qualidade do feed- } \\
\text { back; observação; saber trans- } \\
\text { mitir; explicar bem; saber } \\
\text { orientar; saber aplicar conheci- } \\
\text { mentos técnicos e científicos; } \\
\text { exemplificar }\end{array}$ \\
\hline & avaliação & 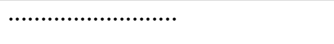 & 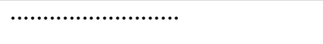 & 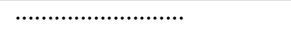 & reflexão \\
\hline \multirow[t]{2}{*}{$\begin{array}{l}\text { outras } \\
\text { caracte- } \\
\text { rísticas } \\
\begin{array}{l}T-n=9 \\
F-n=1\end{array}\end{array}$} & $\begin{array}{l}\text { contexto } \\
\text { trabalho / } \\
\text { W colec- } \\
\text { tivo }\end{array}$ & 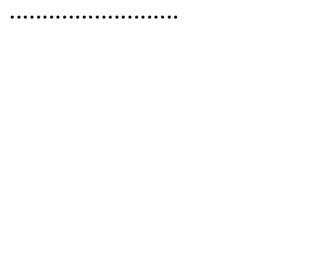 & $\begin{array}{l}\text { não se limitar ao envolvi- } \\
\text { mento desportivo; bom } \\
\text { gestor de competências } \\
\text { individuais, quer dos joga- } \\
\text { dores quer da sua equipa } \\
\text { técnica; bom coordenador } \\
\text { da sua equipa; competên- } \\
\text { cias de gestão }\end{array}$ & trabalhar em equipa & $\ldots$ \\
\hline & $\begin{array}{l}\text { vivências } \\
\text { anterio- } \\
\text { res }\end{array}$ & 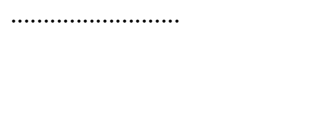 & $\begin{array}{l}\text { experiência; treinador } \\
\text { com algum historial; } \\
\text { conhecer a realidade } \\
\text { nacional/internacional }\end{array}$ & 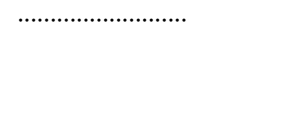 & 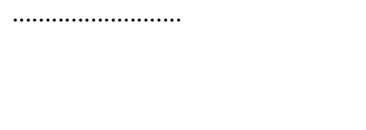 \\
\hline
\end{tabular}

actualizar-se; saber cada vez mais; querer saber mais; actualização; reciclar constantemente; esforçar-se por acrescentar algo; constante actualização curiosidade; necessidade de pesquisa; aprofundar os conhecimentos; constantemente actualizado; investimento; busca conhecimentos científicos e exigente na actualização dos conhecimentos 
que coloca menos termos nesta zona de proximidade (apenas 4 e de natureza diferenciada).

Apesar de tomarmos como referência a ideia desenvolvida por Stoof, Martens, van Merriënboer e Bastiens (46), temos consciência que esta tentativa de agregar os dados e a forma como os associámos (hierarquia e ordem de referência) não nos proporciona mais que uma leitura limitada e muito linear, na medida em que apenas são tidos em conta dados factuais de grandeza e de ordenação, não considerando a ênfase dada por cada respondente, aquando da referência dos termos. Um determinado termo pode ter sido referenciado em último lugar e o respondente atribuir-lhe mais importância comparativamente a outro termo que mencionou em primeiro lugar. No entanto, na nossa opinião, este tipo de análise é importante pois, independentemente da subjectividade que possa estar associada à interpretação efectuada, permite-nos avançar neste percurso sinuoso que nos propusemos percorrer, na tentativa de contribuir para a clarificação do conceito de competência aplicado ao campo profissional do desporto.

\section{Características associadas à competência}

Face às características referenciadas e tomando por referência a síntese das componentes da competência(46) e as dimensões de avaliação da aptidão profissional(13), chegamos às seguintes categorias: características pessoais, características relacionais, ética profissional, conhecimento (subdividido em formação e formação contínua), habilidades/dimensão técnica (subdividas em preparação; realização e avaliação) e outras características (Quadro 4).

As características que os respondentes associam a um profissional competente são múltiplas e dispersas, excedendo mesmo o número de termos referenciados. Das 589 características mencionadas, 506 são diferenciadas, à partida, conseguindo-se apenas reduzir para 451 características, após uma operação de condensação por proximidade semântica. Quando observámos a expressão numérica das características referidas dentro de cada área profissional o panorama mantém-se: o número de características já condensadas oscila entre 86, no grupo de fitness, e 158, no grupo de treinadores.

Ao analisarmos a hierarquia das características mais referenciadas por grupo, verificámos a ausência de aspectos comuns.
Os treinadores assumem o valor mais expressivo na característica liderança (9 menções), seguido da pontualidade (5 menções) e postura pedagógica, resultados, perfeccionismo e conhecimento, todas com 4 menções. A liderança do grupo acrescida de aspectos relacionados com o profissionalismo, o saber lidar com os atletas e o alcançar de resultados, são as características mais relevantes neste grupo.

Nos professores de $E F$, quatro características ganham relevância, apesar de cada uma ser mencionada apenas 4 vezes: relação com os alunos, assíduo, pontual e empenhado.

Os professores de fitness, colocam como característica mais importante a simpatia (4 menções) seguida de um conjunto de características: pontual, conhecimento, actualizar-se, boa relação, boa apresentação, com apenas duas menções cada. O ser capaz de motivar é a característica que assume o topo da hierarquia nos professores de populações especiais ( 6 menções), seguindose a disponibilidade e o conhecimento, ambas com 5 menções, e por último a sensibilidade (4 menções). Tomando como referência a categorização das características em características pessoais, relacionais e de conhecimento (subdivido em formação e formação contínua), no grupo dos professores de EF e de fitness, verificámos que a maior concentração de características recai sobre a categoria conhecimento (associando formação e formação contínua) perfazendo um total de 26 e 20 menções, respectivamente; nos treinadores, é a categoria características pessoais (34 menções), seguida da ética profissional (32 menções); e, nos professores de actividade física adaptada, ética profissional (25 menções), seguida das categorias características relacionais e conhecimento (22 menções cada). A subida da categoria conhecimento, comparativamente aos resultados anteriores, nos professores de EF e de Fitness explica-se pelo número muito expressivo de referências à formação contínua, contribuindo para um aumento da expressão desta categoria. $\mathrm{O}$ facto dos treinadores darem mais expressão às características pessoais e, nos termos, ao conhecimento leva-nos a pensar que a ética profissional, ao se relacionar com termos como profissionalismo é natural que tenha assumido aqui um valor expressivo. Quanto aos professores de populações especiais as questões profissionais expressas anteriormente pelos termos responsabilidade, empenhamento que se colocava 
numa zona de proximidade do núcleo da competência, encontra expressão na categoria ética profissional. Um aspecto que importa evidenciar é o facto das características pessoais referenciadas serem muito diferenciadas de grupo para grupo. Nos professores de EF situam-se em aspectos afectivos (afável, compreensivo, amigo, sensivel, prestável,...) e de controlo (autoridade, flexível, versátil, assertivo, sabe impor-se, interventivo); nos professores de fitness são referidas características relacionadas com a boa disposição (simpatia, bom humor, alegre divertido, ...); nos professores de populações especiais é a afectividade que é realçada (atento, paciente, afável, sensibilidade, atencioso, afectuoso, ...); por último, nos treinadores, claramente distintos dos restantes grupos, as características referenciadas apontam para aspectos relacionados com a capacidade de controlar o processo e ambição nos resultados (liderança, dinâmico, combatividade, perfeccionista, espírito de sacrifício, autoridade, ...).

Quanto aos aspectos relacionais, os grupos de professores de EF e populações especiais apontam para aspectos de relação e de clima positivo; os professores de fitness para se relacionarem com o cliente, dando resposta às suas necessidades; por último, os treinadores dão ênfase aos aspectos de gestão, expressas em referências como: "saber gerir o atleta e o grupo, exigir grande atenção".

Na categoria habilidades, dimensão técnica, ao considerarmos os três momentos fulcrais do processo do ensino-aprendizagem: preparação, realização e avaliação, conseguimos colocar em evidência a dissemelhança do teor de cada momento, nos diferentes grupos, à excepção de pequenos pontos de convergência. Ao nível da preparação detectámos que as preocupações evidenciadas são bastante diferentes. O professor de $E F$ tem apenas uma referência a este momento saber retirar o que é essencial da matéria, o que os alunos têm que dominar - a preocupação está na selecção da matéria de ensino. No outro extremo, está o grupo dos treinadores, com mais referências e com menções centradas no planeamento do treino e da época. Das suas expressões emana uma preocupação em planear meticulosamente - qualidade de preparação dos treinos e época, saber planear, preparar treinos, preparação para que tudo corra o melhor possivel, trabalhador nos planeamentos. Os professores de Fitness centram a preparação no saber colocar objectivos e no saber planear. Quanto aos professores de actividade física adaptada, estes referem o saber estabelecer metas e objectivos e seleccionar exercícios adequados aos alunos.

$\mathrm{Na}$ fase da realização, existem alguns pontos de convergência entre os grupos de professores de EF e de populações especiais. Ambos apontam aspectos relacionados com o ser capaz de motivar os alunos e adequar às suas capacidades [professores de EF (e.g. fazer os alunos gostar de ir à aula, motivar os alunos, chegar a todos os alunos, chegar ao nível dos alunos, chegar ao aluno fazêlo de facto aprender); professores de actividade física adaptada (e g. ir ao encontro deles, manter o interesse deles, capacidade de motivar, adaptar de acordo com os alunos, capacidade de moldar-se à situação, flexibilização perante as turmas)]. Importa ainda referir que as características relacionadas com o conseguir chegar a todos os alunos se traduz em expressões diferenciadas. Enquanto que no professor de EF as questões estão mais centradas na adequação da exigência ao nível dos alunos, nos professores de actividade física adaptada as questões centram-se na adaptação, flexibilização e no moldar, não apenas tendo em conta as capacidades, mas outros aspectos, nomeadamente, na variabilidade do "estar" nas aulas, que oscila, grandemente, desde a participação empenhada ao manter o interesse dos alunos.

Relativamente aos outros dois grupos, a ênfase nos aspectos de realização é claramente distinta. O grupo de fitness valoriza o saber aplicar e a observação no sentido da correcção e adequação das cargas, na garantia da segurança (e g. bom nível técnico, não deixar fazer o que prejudica, observação corporal, não exagerar nas cargas, saber exprimir o que sabe). Os treinadores dão ênfase à transmissão de ideias e à necessidade de uma intervenção sistemática, para a obtenção de melhores desempenhos, acrescida da necessidade de tomar decisões, neste caso decisões interactivas, isto é, no decorrer do processo de treino (e g. saber explicar e transmitir, saber ensinar, saber estar no treino dando feedbacks, actuar durante o treino corrigindo, capacidade de tomar decisões). Outro aspecto que importa evidenciar é o facto dos aspectos da avaliação do ensino, no sentido da reflexão, serem apenas objecto de referência no grupo dos professores de actividade física adaptada.

As variáveis contextuais são objecto de referência no grupo de fitness e dos treinadores, embora com ênfases diferentes. No grupo de fitness são apontados aspec- 
tos relacionados com a necessidade de trabalhar em equipa, e nos treinadores surgem questões mais relacionados com o contexto de trabalho interno e externo, acrescidas de exigências ao nível da capacidade de gestão, com menções como: não se limitar ao envolvimento desportivo, bom gestor de competências individuais, quer dos jogadores quer da sua equipa técnica; bom coordenador da sua equipa, competências de gestão.

O grupo dos treinadores é o único em que as vivências anteriores são referenciadas como característica importante, com expressões como: experiência, treinador com algum historial, conhecer a realidade nacional e internacional.

Em jeito de súmula podemos dizer que o momento de preparação do ensino assume um peso diminuto nos professores de fitness e nos professores de actividade física adaptada, associando-se apenas ao estabelecer de objectivos. Nos treinadores a vertente de preparação é muito mais vincada, denunciando uma preocupação com a planificação de curto e longo prazo, acrescida da necessidade de articulação com a componente de preparação física (sintonizar área da preparação física) e da necessidade de trabalhar a observação (trabalhar nas áreas de observação). A tradição da existência de preparadores físicos nas equipas técnicas, ao nível do desporto rendimento, é claramente evidenciada tanto pela referência anterior como pela menção da necessidade de coordenar uma equipa técnica. Nos professores de EF a centração é claramente na selecção da matéria de ensino (saber retirar o essencial da matéria).

Ao nível da realização, a centração nos alunos sob o ponto vista motivacional e de adequação engloba as principais características referidas pelos professores de $E F$ e de actividade física adaptada, enquanto que os treinadores dão ênfase à intervenção sistemática, no sentido de fazer passar a "ideia de jogo" que pretendem que os seus jogadores apliquem. No grupo do fitness, apesar de a intervenção ser também objecto de preocupação, esta reporta-se ao garantir a segurança ao nível das posturas e da aplicação de cargas.

A componente da avaliação, todos os grupos concentram as referências na observação, na preocupação com a correcção (FB prescritivos), à excepção dos professores de actividade física adaptada, que mencionam características relacionadas com a avaliação do ensino, mais propriamente a autoavaliação, traduzida no termo reflexão.

\section{CONCLUSÕES}

A tentativa encetada neste estudo de identificar o "campo nocional" do conceito de competência conduziu-nos a uma imagem dos "compósitos" tidos como relevantes, pelos profissionais do desporto, na noção de competência.

De destacar a dimensão expressiva do "campo nocional" de competência, fruto do número e diversidade de termos e características identificados e a relevância do conhecimento em todas as áreas ocupacionais. Outro aspecto que importa evidenciar, pela transversalidade e expressão que assume, são os termos relacionados com as questões éticas, sendo que o profissionalismo é o termo com maior expressão. A conjugação destes dois aspectos indica que o conhecimento pode ser considerado um elemento nuclear comum a todas as áreas e o profissionalismo um elemento nuclear ou de grande proximidade ao núcleo da competência, dependendo da área ocupacional. Em torno do núcleo da competência identificaram-se aspectos comuns e divergentes entre as quatro áreas ocupacionais, nomeadamente no que concerne ao número e natureza dos termos e características mencionadas. Contudo a preponderância das divergências denuncia configurações diferentes da "competência" por área ocupacional.

O grupo dos professores de EF, em resultado do número e natureza dos termos identificados - de natureza ética, do saber-fazer e do âmbito da eficiência (resultados), é a configuração de competência que se revela mais lata. Esta imagem ganha consistência aquando da análise das características, pois também aqui a dispersão está presente - incorpora características relacionais, éticas e pessoais.

Os treinadores surgem com a configuração mais circunscrita, centrada em três aspectos: éticos, organizativos e experienciais, sendo que ao nível das características a liderança assume um papel de destaque. Os professores de Fitness, apesar do número de termos em torno do núcleo da competência ser elevado, denunciam uma noção de competência restrita, centrada em aspectos de natureza ética: profissionalismo, responsabilidade, pontualidade e assiduidade, acrescida da simpatia como característica central.

A marca dos professores de Actividade Física Adaptada é essencialmente afectiva - gostar, disponibilidade - dado este que também é evidenciado nas 
características mais referenciadas que se relacionam com a afectividade positiva e a capacidade de motivar. Importa ainda referir que ao nível das características relacionadas com a intervenção profissional, também se verificam disparidades entre as áreas ocupacionais. O momento da preparação assume um papel relevante na área do treino, na EF centra-se na selecção da matéria de ensino e nas áreas do fitness e da actividade física adaptada tem pouca expressão. Relativamente ao momento de realização as questões cognitivas ganham relevo na área do treino enquanto que na área da EF são os aspectos motivacionais. A natureza e restritividade dos dados obtidos, coloca limitações que impedem generalizações, contudo pensamos que foi um passo importante no processo de mapeamento do conceito de competência aplicável aos profissionais do desporto. A necessidade de avançar no processo de clarificação clama por explorações mais profundas e de carácter confirmatório, por forma a se (in) validar as imagens aqui emergentes.

\section{NOTAS}

${ }^{1}$ Campo nocional - conjunto de terminologia preexistente à doutrina, qualquer que fosse o domínio a que pertencesse previamente, tanto podendo tratar-se de palavras da língua como de expressões semiconceptualizadas. Necessidade de verificar sempre qual foi o significação anterior da noção, o campo a que pertenceu, a fim de medir o desvio provocado pela sua integração em novo contexto.

Nota: neste estudo utilizámos a noção de campo nocional de forma restrita, i.e., circunscrita aos termos e características que rodeiam o conceito de competência.

2 Batista, P; Graça, A.; Matos, Z. (2007). Competencia - entre significado y concepto. Contextos Educativos. Revista de Educación, 10: 7-28.

${ }^{3}$ Organismo que congrega especialistas na área da formação em desporto de 28 países europeus, entre os quais se inclui Portugal. No âmbito deste projecto, foram elaborados vários documentos visando construir referenciais para o desenho dos currículos de formação na área do desporto, tendo em consideração a Declaração de Bolonha, os objectivos de Lisboa relativos à Agenda de Educação e Formação 2010 e ainda a Estrutura da Qualificação Profissional na Europa (European Qualification Framework - EQF).

${ }^{4}$ a designação "professor competente" alterava-se, em função da área profissional do inquirido, para: professor de actividade física adaptada, professor de fitness e treinador.

${ }^{5} 1^{\circ}$ nível - sub-consciência que incorpora a motivação e a personalidade; $2^{\circ}$ nível - consciência que incorpora a auto-imagem e papel social; $3^{\circ}$ nível - comportamento que incorpora as habilidades.

\section{CORRESPONDÊNCIA}

Paula Maria Fazendeiro Batista

Faculdade de Desporto da Universidade do Porto

Gabinete de Pedagogia do Desporto - Estágio

Pedagógico

Rua Dr. Plácido Costa, 91

4200-450 Porto

E-mail: paulabatista@fade.up.pt

\section{REFERÊNCIAS}

1. Ashworth P, Saxton J (1990). On "competence". Journal of Further and Higher Education 14:3-25.

2. Barnett R (1994) The limits of competence: knowledge, higher education and society. Bucckingham, UK: SRHE \& Open University Press.

3. Batista P, Graça A, Matos Z (2005). Exploração do conceito de competência aplicado ao campo profissional do pedagogo do desporto. In: Resumos das Comunicações do Congresso Internacional Educação e Trabalho Representações Sociais, Competências e Trajectórias Profissionais. In A. M. Martins; C. Prado de Sousa e L. A. Pardal (Orgs.).Universidade de Aveiro.

4. Berliner DC (1994). Teacher expertise In: Bourne APJ (ed) Teaching and learning in the primary school. Routledge \& Open University PressLondon, pp. 73-79.

5. Boak G (1991). Developing Managerial competences: The management learning contract approach. London: Pitman.

6. Boyatzis RE (1982). The competent manager: a model for effective performance. New york: Wiler.

7. Cheetham G, Chivers G (1996). Towards a holistic model of professional competence. Journal of European Industrial Training 20:20-30.

8. Cheetham G, Chivers G (1998). The reflective (and competent) practitioner: A model of professional competence which seeks to harmonise the reflective practitioner and competence-based approaches. Journal of European Industrial Training 22:267.

9. Chomsky N (1965). Aspects of a theory of syntax. Cambridge, MA: Harvard University Press.

10. Clark TG (2005). Defining a competency framework to shape the professional education of national security master strategists: A Web-based Delphi study. PhD Dissertation. Texas A\&M University, p. 254.

11. Ecke P (1981). Undersuchungen Zum Pädagogischen Können. Berlin: Yolk und Wissen Volkseigener Verlag.

12. Flach H (ed) (1986). Zur Entwicklung des Pädagogischen Könnens in der Lehrerausbildung Volk und Wissen Volkseigener Verlag, Berlin.

13. Formosinho J (2001). A formação prática dos professores: 
da prática docente na instituição de formação à prática pedagógica nas escolas. Revista Portuguesa de Professores, pp. 37-54.

14. Gilbert P, Parlier M (1992). La compétence: du "mot-valise" au concept opératoire. Actualité de la formation permanente: 8-14.

15. Gonzi A, Hager P, Athanasou J (1993). The development of competency-based assessment strategies for the professions:national office of overseas skills recognition research article 8. Canberra: Australian Government Publishing Service.

16. Grossman P (ed) (1990). The Making of a Teacher. Teacher and teacher Education. Teachers College Press New York

17. Hill M, Hill A (2002). Investigação por Questionário. Lisboa: Edições Sílabo.

18. Holmes L (1992). Understanding professional competence: Beyond the limits of functional analysis. Relating Skill and Learning.

19. Keen K (1992). Competence: What is it and how can it be developed? In: Lowyck J, Potter P, Elen J (eds) Instructional design: implementation issues. IBM Education Center, Brussells, pp. 111-122.

20. Kirschner P, Van Vilsteren P, Hummel H, Wigman M (1997). The design of a study environment for acquiring academic and professional competence. Studies in Higher Education 22:151-171.

21. Kouwenhoven W (2003). Designing for competence in Mozambique. Toward a competence-based curriculum for the Faculty of Education of the Eduardo Maondlane University. In:University of Twentw, Enschede, p 450.

22. Le Boterf G (1994). De la compétence: essai sur un attracteur étranger. Les Éditions d'organisation.

23. Lees T, Mabey C, Liefooghe A (2005). In the name of capability': a critical discursive evaluation of competency-based management development. Human Relations 58:1185-1222.

24. Luz T (2000). Competências que marcam a diferença. Dissertação de Doutoramento. Administração, CEPEAD/UFM, Belo Horizonte.

25. Marrelli A, Tondora J, Michael H (2005). Strategies for developing competency models. Administration and Policy in Mental Health Vol. 32:533-561.

26. Matos Z (1989). Para uma definição do conceito e dos pressupostos do desenvolvimento da competência pedagógica. In: Instituto Superior de Educação Física Universidade do Porto, Porto, p. 110.

27. McClelland D (1973). Testing for competence rather than for intellegence. American Psychological Science 9:331-339.

28. Meignant A (1999). A Gestão da Formação. Lisboa: Dom Quixote.

29. Mirabile RJ (1997). Everything you wanted to know about competency modeling. Trainning and Development:73-77.

30. Mish F (1995). In: Merriam-Webster's collegiate dictionary. Merrian-Webster, Inc., Springfield.

31. Mulder M, Weigel T, Collins K (2007). The concept of competence in the development of vocational education and training in selected EU member states: a critical analysis. Routledge.

32. Murray J (1933). Oxford English Dictionary. In: Murray JAH (ed)Clarendon Press, Oxford UK.

33. Parente C (2003). Construção social das competências profissionais: dois estudos de caso em empresas multinacionais do sector metalomecânico. Dissertação de Doutoramento. Faculdade de Letras, UP.
34. Parry S (1996). The quest for competences: competency studies can help you make HR decision, but the results are only as good as the study. Trainning 33:48-56.

35. Partridge E (1938). Macmillan's modern dictionary. In: Partridge E (ed)Macmillan Co, New York.

36. Perrenoud P (1999). Construir compêtencias é virar as costas aos saberes? . Pátio - Revista Pedagógica 11:15-19.

37. Perrenoud P (1999). Dix nouvelles competènces pour enseigner. Invitation au Voyage. Paris: ESF.

38. Sandberg J (2000). Understanding Human Competence at Work: An Interpretative approach. Academy of Management Journal 43:9-25.

39. Sandberg J (2001). Understanding the basis for competence development In: Velde C (ed) International perspectives on competence in the workplace. Dordrecht: Kluwer Academic Press.

40. Schippmann J, Ash R, Batista M, Carr L, Eyde L, Hesketh B, Kehoe J, Pearlman K, Prien E (2000). The practice of competency modelling. Personnell Psychology 53:703-740.

41. Scott G (1952). Swan's Anglo American dictionary. In: Scott GR (ed)Library Publishers, New York, NY.

42. Shulman L (1987). Assessment for teaching: an initiative for the profession. Phi Delta Kappan 69:38-44.

43. Spencer LSS (ed) (1993). Competence at Work: Models for superior performance. John Wiley \& Sons, Inc., United States of America.

44. Spitzberg B (1983). Communication competence as knowledge, skill, and impression. In: Communication Education. pp. 323-329.

45. Stoof A (2005). Tools for the identification and description of competencies. In:Open Universiteit Nederland, Heerlen.

46. Stoof A, Martens RL, van Merriënboer JJ, Bastiaens TJ (2002). The Boundary Approach of Competence: A Constructivist Aid for Understanding and Using the Concept of Competence. Human Resource Development Review 1:345-365.

47. Tate W (1995). Developing Managerial Competence: A critical guide to methods and materials. London: Gower.

48. Velve C (1999). crossing borders: an alternative conception of competence and implications of professional practice in the workplace. . Journal of Vocational Education and Training 51:437-447.

49. Velve C (2000). An alternate conception of competence: implications for vocational education and practice. In: UTS research Centre Vocational Education \& Trainning Working Knowledge: Productive learning at work. . p 1-11.University of Technology Sydney, New south Wales, Australia.

50. Weinert FE (2001). Concept of competence: a conceptual clarification. In: Rychen DS, Sagalnik LH (eds) Defining and selecting key competencies. Hogrefe \& Huber, Göttingen, pp. 45-66.

51. Westera W (2001) Competences in education: a confusion of tongues. Journal of Curriculum Studies 33:75-88.

52. Wiemann J, Blacklund P (1980). Current theory and research in communicative competence. In: Review of Educational Research. pp. 185-199.

53. Willis S, Dubin S (1990). Maintaining professional competence. San Francisco: Jossey-Bass.

54. Winterton JW, R. (ed) (1999). Developing Managerial Competence. Routledge, London.

55. Woodruffe C (1991). Competent by any other name. Personnel Management:30-33. 